\title{
Drought Utilization Management of Surface and Ground Water (Case study: Qaryat- Al-Arab Watershed)
}

\author{
E. Fadaei-Kermani ${ }^{1 *}$, G. A. Barani' ${ }^{1}$, R. Memarzadeh ${ }^{2}$ \\ ${ }^{1}$ Department of Civil Engineering, Faculty of Engineering, Shahid Bahonar University of Kerman, Kerman, Iran \\ ${ }^{2}$ Department of Civil Engineering, Faculty of Engineering, Vali-e-Asr University of Rafsanjan, Rafsanjan, Iran
}

\section{$P A P E R \quad I N F O$}

\section{Paper history:}

Received 28 October 2019

Accepted in revised form 24 November 2019

\section{Keywords:}

Water Resource Management

Drought Monitoring

$K$ Nearest Neighbor Model

Standardized Precipitation Index

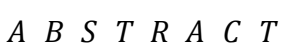

Inattention to water as a key parameter of sustainable development, leads the long-term and planned management for the water to be marginalized. In this regard, proper and optimal utilization planning and management of surface and ground water resources is very important. In this study drought utilization motitoring and management of surface and ground water resources for the Qaryat-Al-Arab watershed, located in Kerman, has been investigated. Kerman is among the regions of Iran that does not benefit enough precipitation. At first the region drought status was predicted and monitored using $K$ nearest neighbor (KNN) model. The present model gave appropriate estimations of drought status for the study area, and reasonable values of the statistical coefficients showed that the present model is efficient and suitable. Finally due to the drought status and classification and also surface and ground water resources condition, the water resources allocation respect to the management modeling were proposed for the study area.

\section{INTRODUCTION}

Iran, with an average annual precipitation of $240-250 \mathrm{~mm}$, is among the regions of the world that does not benefit enough rainfall. The main part of the country is covered by the arid and low-water areas, thus, water has played a crucial role in its economic development since long time ago. Hence, proper management of surface water and especially ground water utilization has a significant role in maintenance and optimized usage of water resources [1]. When the issue of water resource constraints is raised, the proper management of the sustainable and economical use of these resources is also being addressed. Thus, one of the main factors limiting the development of the agricultural sector in Iran is water. In this regard, the experts believe that, if there were no restrictions on water resources, most of the country lands could have been cultivated and planted [2].

Due to fluctuations in the surface water resources, despite the high and considerable volume of water, they cannot be taken as a reliable source for supplying water for various applications, especially in the agricultural sector irrigation. The level of surface and ground water resources utilization in each region is directly related to the water needed for agricultural products irrigation in that area. When the surface water supply is less than the amount demanded, the combined utilization of surface and ground water resources can make water supply more secure and increase the availability of the irrigation water when needed. Particularly in the event of drought, the stabilizing role of the water supply is more evident. Harvesting more than feeding on ground water aquifers, disturbs the system balance, lacks the stability and reduces the storage of ground water aquifers and ultimately makes the sustainable agriculture impossible. Therefore, in order to achieve sustainable development of agricultural sector, balancing between nutrition and harvesting underground resources is of a great importance. Proper utilization of surface and ground water resources in this sector can help to establish this balance and ultimately help to sustainable exploitation of water resources $[3,4]$. On the other hand, the proper management of surface water has an important role in supplying the water needs for the agriculture and industry. With increasing water requirements for various uses, acceptability in optimal utilization of surface and ground water resources has been increased. This is a strong reason for the need for special attention and a new approach to the issue of proper management of surface and ground water resources [4].

Considering the importance of the optimal and proper exploitation of surface and ground water resources, remarkable studies have been carried out on this issue at the 
national and international levels. Calow et al. [5] investigated the distinct groundwater systems character and their reaction to predominant and changing environmental conditions in Drought-prone Areas of Africa. White et al. [6] investigated the effects of climate impacts in water resources planning and management. In various researches the conjunctive management of surface and groundwater resources has been considered as a solution for proper utilization of water resources [4, 7-9].

In this study, the management of surface and ground water utilization with emphasis on drought conditions for QaryatAl-Arab watershed in Kerman province has been investigated. Kerman province is one of the provinces in Iran with low rainfall, and has always been in shortage of water resources. On the other hand, Qaryat-Al-Arab watershed is one of the main sources of Kerman fresh water supply. Therefore, proper management and optimization of the water resources of this area, especially in drought conditions, which water shortage crisis reaches its maximum importance, can play a significant role in helping to solve the issue of water shortage and supply of water resources in this province.

\section{METHOD AND MATERIALS}

\section{Case study}

Qaryat-Al-Arab watershed (city of Golzar) is located in Kerman Province, south eastern of Iran. Geographically, this area is located at 29.7108 North and 57.0408 East on Iran map and at 2312 meters above the sea level. This city population is about 12,000 people and covers an area of 330 hectares. The geographical location of the area has been shown in Figure 1.

Qaryat-Al-Arab is one of the most important sources of fresh water supply in Kerman. The existence of springs, qanats, and numerous rivers in this area has added value to the importance of this region as a source of water supply. The situation of Golzar water resources has been presented on Table 1 .

\section{Drought monitoring and prediction}

Drought is a very important and destructive weather phenomenon which affects almost all areas of the planet. It is

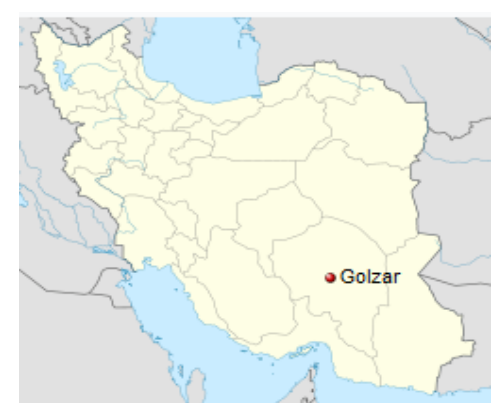

Figure 1. Geographical location of Qaryat-Al-Arab watershed (city of Golzar)

TABLE 1. The water resources situation in study area

\begin{tabular}{cccc}
\hline $\begin{array}{c}\text { Number } \\
\text { of qanats }\end{array}$ & $\begin{array}{c}\text { Number of } \\
\text { natural springs }\end{array}$ & $\begin{array}{c}\text { Important } \\
\text { Rivers }\end{array}$ & $\begin{array}{c}\text { Number of } \\
\text { active wells }\end{array}$ \\
\hline 73 & 4 & Chari Haft-koosk & 74 \\
\hline
\end{tabular}

usually caused by a reduction in rainfall over a given period of time. This phenomenon begins slowly and its impact appears gradually over a relatively long time period in various sectors, including agriculture, water, environment, economics, and so on [10].

Drought prediction plays a very important role in reducing the damages caused by this phenomenon in water resources systems. Drought monitoring systems are one of the important tools to take appropriate measures to deal with the effects of drought disruption, which can provide timely information on the durability, severity and development of drought in a region. Considering that reducing the rainfall is a major issue in drought incidence, most of these systems and indices used in drought monitoring are based on rainfall [11].

In general, drought indices are applied to predict and monitor this phenomenon. The main objective of using these indices is to define the characteristics of this phenomenon quantitatively. There are various indices have been developed to quantify and monitor drought condition including: rainfall anomaly index (RAI) [12], Palmer drought severity index (PDSI) [13], Bhalme and Mooly drought index (BMDI) [14], reclamation drought index (RDI) [15], standardized precipitation index (SPI) [16] and etc.

The standardized precipitation index (SPI) proposed by McKee et al. [16] to enhance the detection of onset and monitoring of drought for numerous time scales. The SPI is calculated, according to the long-range records of precipitation data for a desirable period, and then a probability distribution (most likely gamma distribution) can be matched to the long-range data records. Using following equations, a $Z$-standard normal distribution of the cumulative probability can be obtained with variance of one and mean zero.

$$
\begin{aligned}
& Z=S P I=-\left[t-\frac{C_{0}+C_{1} t+C_{2} t^{2}}{1+d_{1} t+d_{2} t^{2}+d_{3} t^{3}}\right] \\
& t=\sqrt{\ln \left[\frac{1}{H(x)^{2}}\right]} \quad \begin{array}{c}
0<H(x) \leq 0.5 \\
Z=S P I=+\left[t-\frac{C_{0}+C_{1} t+C_{2} t^{2}}{1+d_{1} t+d_{2} t^{2}+d_{3} t^{3}}\right] \\
t=\sqrt{\ln \left[\frac{1}{1-H(x)^{2}}\right]} \quad 0.5<H(x) \leq 1
\end{array}
\end{aligned}
$$

where the constants $C_{1}$ to $C_{3}$ and $d_{1}$ to $d_{3}$ can be computed as follows, and $H_{(x)}$ refers to cumulative probability function.

$$
\begin{array}{ll}
d_{1}=1.432788 & C_{1}=2.51557 \\
d_{2}=0.189269 & C_{2}=0.802853 \\
d_{3}=0.001308 & C_{3}=0.010328
\end{array}
$$

After the numerous time series were obtained according to precipitation data, this data is sorted in increasing order. Then the empirical probability distribution is computed as follows:

$$
E C P=\frac{m}{n+1}
$$

where $n$ refers to the total precipitation data number, and $m$ expresses the row number of sorted precipitation data. The classification system defined drought intensities resulting from SPI is shown in Table 2.

\section{Nearest neighbor algorithm}

Nonparametric machine learning algorithm such as $k$-nearest neighbor algorithm $(k-\mathrm{NN})$ can be widely applied in data mining and pattern recognition. In this method a sample 
TABLE 2. The SPI drought classification [16]

\begin{tabular}{lcc}
\hline SPI Values & Drought Status & Class \\
\hline+2 and more & extremely wet & 1 \\
1.5 to 1.99 & very wet & 2 \\
1 to 1.49 & moderately wet & 3 \\
0.99 to -0.99 & near normal & 4 \\
-1.49 to -1 & moderately dry & 5 \\
-1.99 to -1.5 & very dry & 6 \\
-2 and less & extremely dry & 7 \\
\hline
\end{tabular}

which is unknown is classified according to the known classification of data in its neighborhoods $[17,18]$.

At first in the method, the distance between training and test data should be determined. For example Euclidean distance can be applied as follows:

$$
d(X, Y)=\sqrt{\sum_{i=1}^{n}\left(x_{i}-y_{i}\right)^{2}}
$$

where $X$ expresses training data which can has specific parameters $\left(x_{I}\right.$ to $\left.x_{n}\right)$, and $Y$ expresses test data with specific parameters $\left(y_{1}\right.$ to $\left.y_{n}\right)$.

$X=\left(x_{1}, x_{2}, \ldots, x_{n}\right)$
$Y=\left(y_{1}, y_{2}, \ldots, y_{n}\right)$

The calculated distances of all the attributes in the training set are sorted, and the nearest neighbors can be determined according to maximum similarity. Then the $K$ number of nearest neighbors should be calculated. The optimum value for $K$ nearest of the neighbors is acquired using $n$-fold cross validation method. The method deals with dividing the data set into $n$ approximately equal-sized parts. For each part (the $n$th part) the model is fitted to the other data parts $(n-1)$. After calculating the model error rate for all values of $K(\mathrm{k}=1,2$, $\ldots, K)$, the best value of $K$ with minimum error rate can be obtained [19].

\section{Model of water resource management}

Management and planning of surface and ground water resources, respect to the long-term quantitative and qualitative limitations, require special attention to understanding the governing components and also the problem formulation. These components includes distribution of water resources, drainage status, characteristics and capacity of water transmission and distribution networks, water demands, ecology and environment of the region and etc. [20].
The application of optimization techniques can be a useful approach in adoption of design strategies for the utilization management of surface and ground water resources. These models are mostly based on mathematical and optimization algorithms. In general, the overall structure of a proposed management model for surface and ground water resources can be as follow:

$$
\begin{array}{ll}
\text { Minimaze } \mathrm{F}=\left\{\sum(\text { Demand }- \text { Supply })^{2}\right. & \text { for Demand } \geq \text { Supply } \\
0 & \text { for Demand }<\text { Supply }
\end{array}
$$

In the model, the goal is to minimize the function $F$, (optimization of water consumption), under the constraints governing the problem G. Supply refers to the all available surface and underground water resources in the region, and Demand refers to the various uses of water.

\section{RESULTS AND DISCUSSIONS}

In this paper, the precipitation data of Qaryat-Al-Arab watershed (city of Golzar) from 1967 to 2013 were utilizedsed. According to the precipitation data, standard normal distribution function and moving time series for different time scales were determined. Then the standard precipitation index was calculated. Figures 2 to 6 present the standard normal probability distribution function and the precipitation cumulative probability distribution function for 3-, 6-, 12-, 24- and 48-month time scales.

According to the standard normal probability distribution function and the precipitation cumulative probability distribution function, the SPI values for different time scales were calculated. According to the calculated values of SPI, the KNN model was applied to determine the most probably drought condition in the study area for different years. At first the calculated SPI values should be normalized using the following equation:

$$
X^{\prime}=\frac{x-\bar{x}}{\sigma(x)}
$$

In Equation (6), $X^{\prime}$ refers to the normalized attribute value, $\sigma(x)$ and $\bar{X}$ represent the standard deviation and mean of the attribute in the reference data set.

After that, the best value of the $\mathrm{K}$ was calculated by fourfold-cross validation approach. Figure 7 represents the method precision respect to the SSE coefficient (Sum of Squares Error).
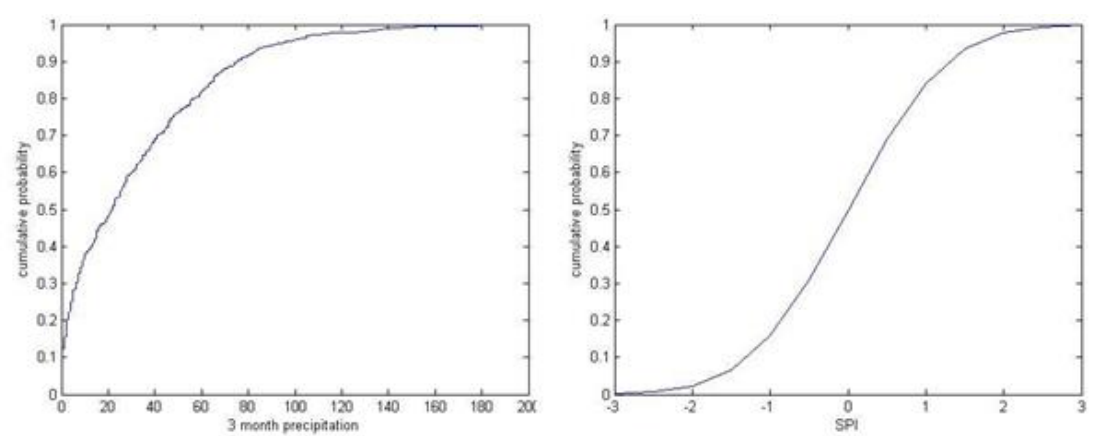

Figure 2. Cumulative probability distribution function and 3-month SPI values 

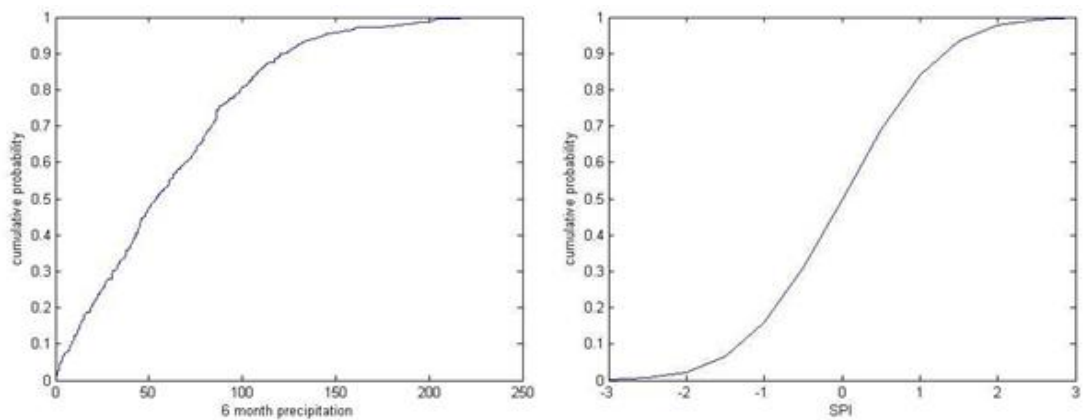

Figure 3. Cumulative probability distribution function and 6-month SPI values
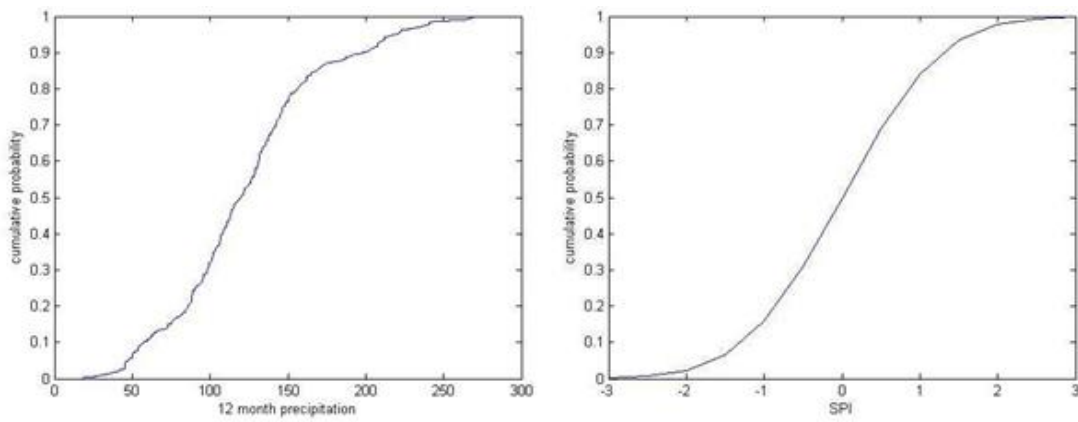

Figure 4. Cumulative probability distribution function and 12-month SPI values
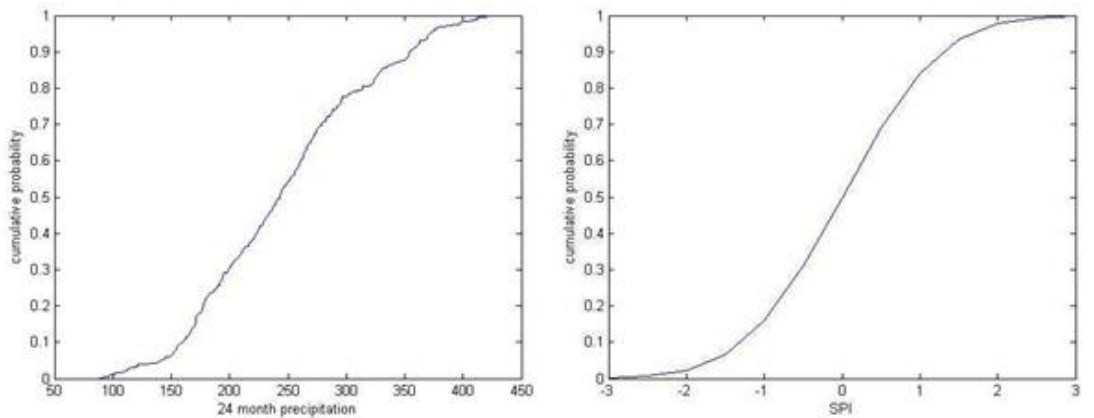

Figure 5. Cumulative probability distribution function and 24-month SPI values
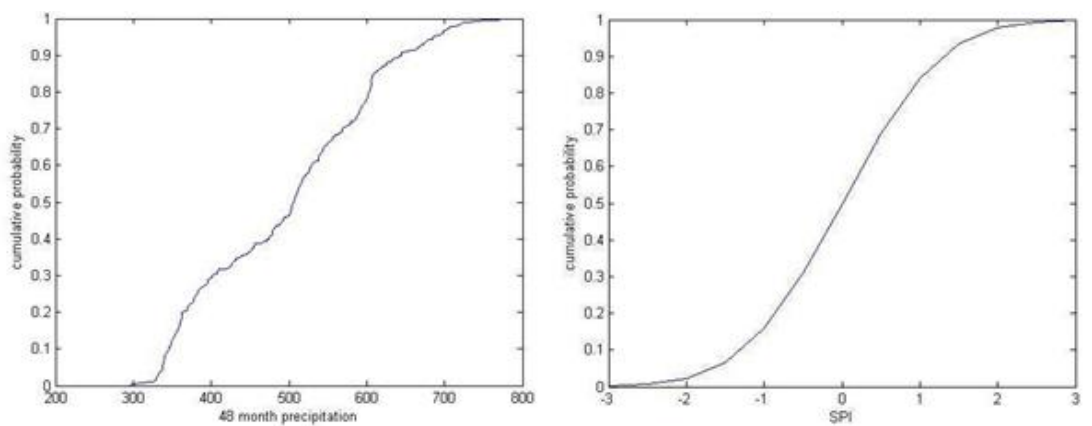

Figure 6. Cumulative probability distribution function and 48-month SPI values

It can be seen that three values of $\mathrm{K}$ including 15,16 and 20 have the same lowest error rate. Therefore, the value of $\mathrm{K}$ equal to 20 was chosen for the rest of calculations. After determining the best value of the $\mathrm{K}$ from the nearest neighbors attributes, the most probably drought status of the study area was determined using the K-NN model. Figure 8 illustrates the region drought classification and situation respect to the standard precipitation index (SPI) for duration of the desirable time periods.

To evaluate the present model precision and accuracy, some statistical coefficients including the coefficient of Pearson's $r(\mathrm{r})$, root mean square error (RMSE), mean absolute error (MAE) and coefficient of residual mass (CRM) were calculated by the following expressions [21]: 


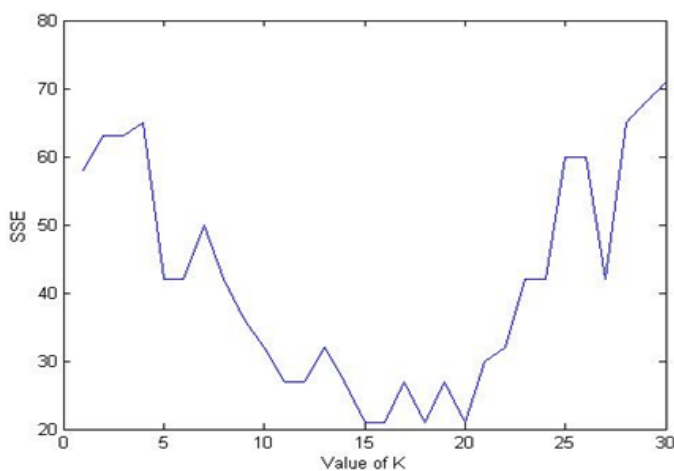

Figure 7. The K-NN model error rate in fourfold-cross validation method

$$
\begin{aligned}
& r=\frac{n\left[\sum_{i=1}^{n} y_{i} x_{i}\right]-\left[\sum_{i=1}^{n} y_{i}\right]\left[\sum_{i=1}^{n} x_{i}\right]}{\sqrt{\left[n \sum_{i=1}^{n} y_{i}^{2}-\left(\sum_{i=1}^{n} y_{i}\right)^{2}\right]\left[n \sum_{i=1}^{n} x_{i}^{2}-\left(\sum_{i=1}^{n} x_{i}\right)^{2}\right]}} \\
& R M S E=\left[\frac{\sum_{i=1}^{n}\left(x_{i}-y_{i}\right)^{2}}{n}\right]^{0.5} \\
& M A E=\frac{\sum_{i=1}^{n}\left|x_{i}-y_{i}\right|}{n} \\
& C R M=\frac{\left(\sum_{i=1}^{n} x_{i}\right)-\left(\sum_{i=1}^{n} y_{i}\right)}{\sum_{i=1}^{n} x_{i}}
\end{aligned}
$$

Table 3 indicates the values of these coefficients. Due to obtained results presented in Table 3 , high value of the Pearson correlation coefficient shows strong relationship between variables, and the low RMSE, MAE and CRM values show low error and reasonable precision of the present model.

Monitoring and prediction of drought status in a region play a remarkable role in appropriate management of water resources. By evaluating and monitoring the Qaryat-Al-Arab watershed water resources, the situation of water resources summarized in Tables 4 and 5 and illustrated in Figure 9.

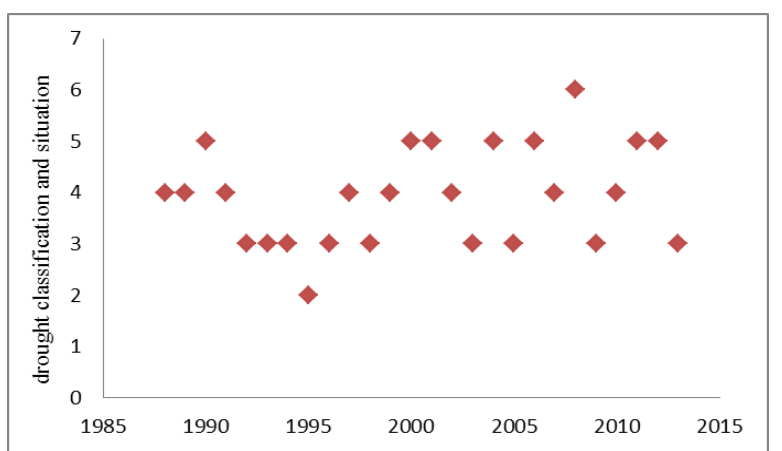

Figure 8. Geographical location of Qaryat-Al-Arab watershed (city of Golzar)

TABLE 3. Evaluation and precision of the K-NN model

\begin{tabular}{lccc}
\hline $\mathbf{r}$ & RMSE & MAE & CRM \\
\hline 0.866 & 0.124 & 0.108 & 0.0019 \\
\hline
\end{tabular}

TABLE 4. The situation of qanats in study area

\begin{tabular}{lccccc}
\hline Number & $\begin{array}{c}\text { Annual } \\
\text { Discharge } \\
\left(\mathbf{M}^{\mathbf{3}}\right)\end{array}$ & $\begin{array}{c}\text { Utilization } \\
\text { days in a } \\
\text { year }\end{array}$ & $\begin{array}{c}\text { Utilization } \\
\text { hours }\end{array}$ & $\begin{array}{c}\text { Average } \\
\text { Discharge } \\
\left(\mathbf{M}^{\mathbf{3}}\right)\end{array}$ & $\begin{array}{c}\text { Average } \\
\text { temperature }\end{array}$ \\
\hline 73 & 13560480 & 365 & 24 & 193721.1 & $15.7^{\circ} \mathrm{C}$ \\
\hline
\end{tabular}

TABLE 5. The situation of natural springs in study area

\begin{tabular}{lccccc}
\hline Number & $\begin{array}{c}\text { Annual } \\
\text { Discharge } \\
\left(\mathbf{M}^{\mathbf{3}}\right)\end{array}$ & $\begin{array}{c}\text { Utilization } \\
\text { days in a } \\
\text { year }\end{array}$ & $\begin{array}{c}\text { Utilization } \\
\text { hours }\end{array}$ & $\begin{array}{c}\text { Average } \\
\text { Discharge } \\
\left(\mathbf{M}^{\mathbf{3}}\right)\end{array}$ & situation \\
\hline 4 & 126144 & 365 & 24 & 31536 & permanent \\
\hline
\end{tabular}

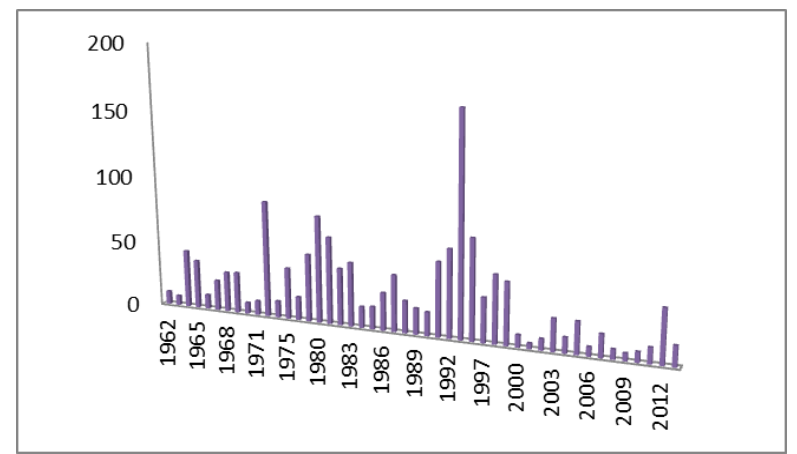

Figure 9. Average Discharge of streams in study area $\left(\mathrm{mM}^{3}\right)$

Regarding the analysis of the area drought condition and the results are presented in Figure 8. It can be found out that in recent years, the area has suffered from rainfall below normal and relatively drought conditions. Based on the presented results and decision making diagrams, and the annual precipitation in the region, drought and water resources conditions can be estimated. Finally, the best decision is made for utilization of surface and ground water resources. The allocation of water resources during year 2011 presented in Table 6 and Figure 10.

TABLE 6. The allocation of water resources during year 2011

\begin{tabular}{lcccc}
\hline $\begin{array}{l}\text { Drought } \\
\text { Status }\end{array}$ & $\begin{array}{c}\text { Drought } \\
\text { class }\end{array}$ & $\begin{array}{c}\text { average annual } \\
\text { piezometric surface }\end{array}$ & $\begin{array}{c}\text { Surface } \\
\text { water }\end{array}$ & $\begin{array}{c}\text { Ground } \\
\text { water }\end{array}$ \\
\hline $\begin{array}{l}\text { moderately } \\
\text { dry }\end{array}$ & 5 & 50.59743 & 47 percent & 53 percent \\
\hline
\end{tabular}

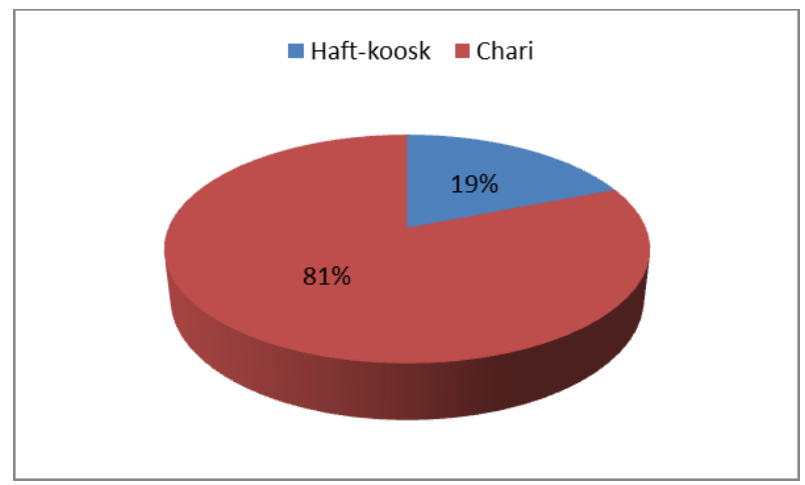

Figure 10. The allocation of rivers in the study area 


\section{CONCLUSIONS}

In the present paper, the utilization management of QaryatAl-Arab watershed surface and ground water resources with emphasizing the drought conditions was investigated. At first the situation of water resources and also hydrological parameters in the study area ware examined. Using the $K$ nearest neighbor approach the most probably drought situation of the region was determined based on SPI index. The model results showed that the region has faced moderate to intense drought conditions in recent years that are consistent with local observations. Evaluation of the proposed method with statistical coefficients including $(\mathrm{r}=0.866)$, $(\mathrm{RMSE}=0.124),(\mathrm{MAE}=0.108)$ and $(\mathrm{CRM}=0.0019)$ indicated that the proposed model is efficient and accurate. Then according to the drought status and surface and ground water resources conditions, the allocations of water resources respect to the management modeling were projected for the study area.

\section{REFERENCES}

1. Kermani, E.F., Abbas Barani, G. and Javad Khanjani, M., 2014. Developing a framework for compatibility analysis of predictive climatic variables distribution with reference evapotranspiration in probabilistic analysis of water requirement. Journal of Applied Research in Water and Wastewater, 1(2), pp.66-73.

2. Noory, H., Van Der Zee, S.E.A.T.M., Liaghat, A.M., Parsinejad, M. and Van Dam, J.C., 2011. Distributed agro-hydrological modeling with SWAP to improve water and salt management of the Voshmgir Irrigation and Drainage Network in Northern Iran. Agricultural Water Management, 98(6), pp.1062-1070.

3. Tian, Y., Zheng, Y., Wu, B., Wu, X., Liu, J. and Zheng, C., 2015. Modeling surface water-groundwater interaction in arid and semiarid regions with intensive agriculture. Environmental Modelling \& Software, 63, pp.170-184.

4. Seo, S.B., Mahinthakumar, G., Sankarasubramanian, A. and Kumar, M., 2018. Conjunctive management of surface water and groundwater resources under drought conditions using a fully coupled hydrological model. Journal of Water Resources Planning and Management, 144(9), pp.1-11.

5. Calow, R.C., Robins, N.S., MacDonald, A.M., MacDonald, D.M., Gibbs, B.R., Orpen, W.R., Mtembezeka, P., Andrews, A.J. and Appiah, S.O., 1997. Groundwater management in drought-prone areas of Africa. International Journal of Water Resources Development, 13(2), pp.241-262.

6. White, K.D., Vaddey, S.V., Hamlet, A.F., Cohen, S., Neilsen, D. and Taylor, W., 2006. Integrating climate impacts in water resource planning and management. In 13th International Conference on Cold Regions Engineering, United States, pp. 1-11.
7. Knapp, K.C. and Olson, L.J., 1995. The economics of conjunctive groundwater management with stochastic surface supplies. Journal of Environmental Economics and Management, 28(3), pp.340356.

8. Pulido-Velázquez, M., Andreu, J. and Sahuquillo, A., 2006 Economic optimization of conjunctive use of surface water and groundwater at the basin scale. Journal of Water Resources Planning and Management, 132(6), pp.454-467.

9. Eslamian, S., Sayahi, M. and Khosravi, B., 2016. Conjunctive Use of Water Reuse and Urban Water. In Urban Water Reuse Handbook, CRC Press.

10. Fadaei-Kermani, E., Barani, G.A. and Ghaeini-Hessaroeyeh, M., 2017. Drought Monitoring and Prediction using K-Nearest Neighbor Algorithm. Journal of AI and Data Mining, 5(2), pp.319-325.

11. Mishra, A.K. and Singh, V.P., 2010. A review of drought concepts. Journal of Hydrology, 391(1-2), pp.202-216.

12. Van-rooy, M.P., 1965. A Rainfall Anomaly Index (RAI), Independent of the Time and Space. Notos, 14, 43-48.

13. Palmer, W.C., 1968. Keeping track of crop moisture conditions, nationwide: The new crop moisture index. Weatherwise, 21, 156161.

14. Bhalme, H.N. and Mooley, D.A., 1980. Large-scale droughts/floods and monsoon circulation. Monthly Weather Review, 108(8), pp.1197-1211.

15. Weghorst, K., 1996, June. The reclamation drought index: Guidelines and practical applications. In North American Water and Environment Congress \& Destructive Water, United States, pp. 637 642

16. McKee, T.B., Doesken, N.J. and Kleist, J., 1993, January. The relationship of drought frequency and duration to time scales. In Proceedings of the 8th Conference on Applied Climatology (Vol. 17, No. 22,), Boston, MA: American Meteorological Society, pp. 179 183.

17. Dhaliwal, D.S., Sandhu, P.S. and Panda, S.N., 2011. Enhanced Knearest neighbor algorithm. World Academy of Science, Engineering and Technology, 73, pp.681-685.

18. Fadaei Kermani, E., Barani, G.A. and Ghaeini-Hessaroeyeh, M., 2015. Prediction of cavitation damage on spillway using K-neares neighbor modeling. Water Science and Technology, 71(3), pp.347352 .

19. Fadaei Kermani, E., Barani, G.A. and Ghaeini-Hessaroeyeh, M., 2018. Cavitation Damage Prediction on Dam Spillways using FuzzyKNN Modeling. Journal of Applied Fluid Mechanics, 11(2), pp 323-329.

20. Wu, B., Zheng, Y., Wu, X., Tian, Y., Han, F., Liu, J. and Zheng, C., 2015. Optimizing water resources management in large river basins with integrated surface water-groundwater modeling: A surrogatebased approach. Water Resources Research, 51(4), pp.2153-2173.

21. Dashtaki, S.G., Homaee, M., Mahdian, M.H. and Kouchakzadeh, M., 2009. Site-dependence performance of infiltration models. Water Resources Management, 23(13), pp.2777-2790.

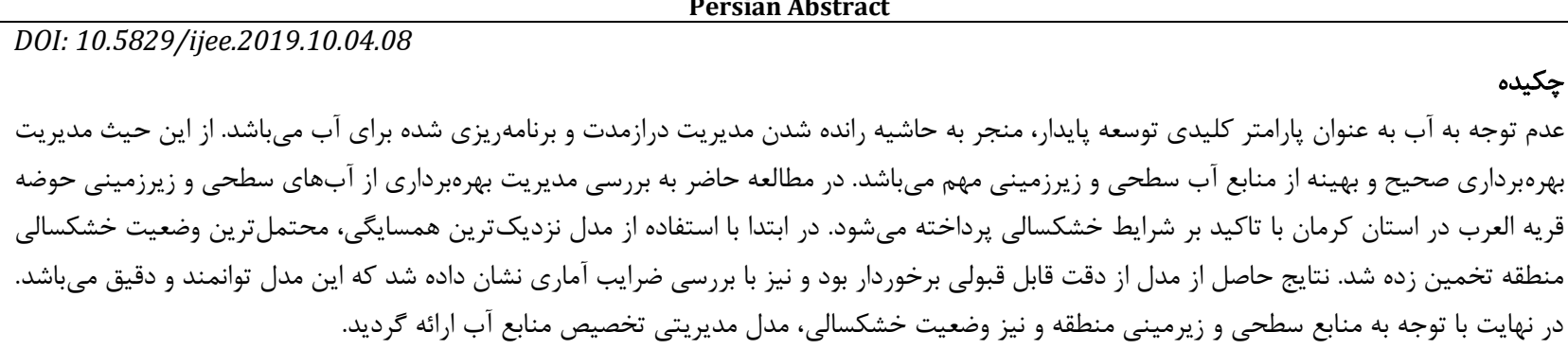

